\title{
Micromorphology and adhesive performance of Er:YAG laser-treated dentin of primary teeth
}

\author{
Simon Flury • Tamara Koch • Anne Peutzfeldt • \\ Adrian Lussi
}

Received: 9 August 2010 /Accepted: 30 December 2010 /Published online: 5 February 2011

(C) Springer-Verlag London Ltd 2012

\begin{abstract}
This study evaluated (1) the micromorphology by scanning electron microscopy (SEM) and (2) the adhesive performance by microtensile bond strength ( $\mu$ TBS) of diamond bur-treated dentin compared to Er: YAG laser-treated dentin of human primary teeth. (1) For qualitative SEM evaluation, dentin of 18 second primary molars ( $n=3 /$ method) was treated with either diamond bur as a control (group 1a: $40 \mu \mathrm{m}$ diamond bur only (clinical situation); group $1 \mathrm{~b}$ : grinding $+40 \mu \mathrm{m}$ diamond bur) or with Er:YAG laser (group 2a (clinical situation, manufacturer's settings): $200 \mathrm{~mJ} / 25 \mathrm{~Hz}(5 \mathrm{~W})+100 \mathrm{~mJ} / 35 \mathrm{~Hz}$ $(3.5 \mathrm{~W})$ laser only; group $2 \mathrm{~b}$ (experimental setting "high"): grinding $+400 \mathrm{~mJ} / 20 \mathrm{~Hz}(8 \mathrm{~W})$; group 2c (manufacturer's setting "finishing"): grinding $+100 \mathrm{~mJ} /$ $35 \mathrm{~Hz}(3.5 \mathrm{~W})$; group $2 \mathrm{~d}$ (experimental setting "low"): grinding $+50 \mathrm{~mJ} / 35 \mathrm{~Hz}(1.75 \mathrm{~W}))$. (2) For evaluation of adhesive performance, 64 second primary molars were divided into four groups and treated as described for
\end{abstract}

Electronic supplementary material The online version of this article (doi:10.1007/s10103-011-0882-5) contains supplementary material, which is available to authorized users.

S. Flury $(\bowtie) \cdot$ T. Koch $\cdot$ A. Peutzfeldt $\cdot$ A. Lussi

Department of Preventive, Restorative and Pediatric Dentistry,

School of Dental Medicine, University of Bern,

Freiburgstrasse 7,

3010 Bern, Switzerland

e-mail: simon.flury@zmk.unibe.ch

T. Koch

e-mail: tamara.koch@zmk.unibe.ch

A. Peutzfeldt

e-mail: anne.peutzfeldt@zmk.unibe.ch

A. Lussi

e-mail: adrian.lussi@zmk.unibe.ch group $1 \mathrm{~b}$ and groups $2 \mathrm{~b} / \mathrm{c} / \mathrm{d}$ ( $n=16 /$ method), and $\mu$ TBS of Clearfil SE/Clearfil Majesty Esthetic to dentin was measured. The SEM micrographs were qualitatively analyzed. The $\mu$ TBS values were compared with a Kruskal-Wallis test. The significance level was set at $\alpha=$ 0.05. SEM micrographs showed the typical micromorphologies with a smear layer for the diamond bur groups and open dentin tubules for all laser-treated groups. However, in group $2 \mathrm{~d}$, the laser beam had insufficiently irradiated the dentin area, rendering the underlying ground surface partly visible. There were no statistically significant differences between $\mu$ TBS values of the four groups $(p=0.394)$. This suggests that Er:YAG laser treatment of dentin of primary molars provides bond strengths similar to those obtained following diamond bur treatment.

Keywords Erbium:yttrium-aluminum-garnet · Scanning electron microscopy (SEM) · Microtensile bond strength

\section{Introduction}

The erbium-doped yttrium aluminum garnet laser (Er:YAG laser) is an alternative used in pediatric dentistry to prepare dental hard tissue. The Er:YAG laser can replace the conventional dental drill for caries removal and cavity preparation especially in anxious children due to a less strident noise and diminished vibrations compared to bur drilling [1-3]. Reportedly, the need for anesthesia is also reduced $[1,4]$.

The Er:YAG laser promotes minimal and conservative preparation. This is attributed to the Er:YAG laser's property to emit waves in the mid-infrared $(\lambda=2.94 \mu \mathrm{m})$ region that falls in an area of spectrum with high absorption peaks in both water and hydroxyapatite [1, 
5]. It is a safe and effective method for removing cariesaffected hard tissue $[2,6]$ and in contrast to other laser types, Er:YAG laser irradiation does not seem to lead to irreversible alterations of the pulp or to significant thermal and structural damage in dental tissues [1,6-8]. Nevertheless, the Er:YAG laser generates a surface micromorphology that differs strongly from that created by tooth preparation with burs: Laser-treated dentin is not covered by the smear layer normally produced by rotating instruments [2, 5, 7, 9]. Micromorphology of dentin is of importance when restoring a cavity with adhesive filling materials. As Er:YAG laser-irradiated dentin differs strongly from dentin prepared with a bur, it is likely that conditioning and pretreatment steps have to be adjusted for sufficient dentin adhesion.

The adhesive potential of laser-treated dentin is controversially discussed in literature [10]. Some studies claim that laser-treated dentin is favorable for adhesive procedures $[5,11]$. Other studies have reported no difference between laser and bur [12-14] treatment, while others have found laser treatment to negatively influence the adhesive dentin interface $[3,7,8,15]$.

Most of these studies were carried out on permanent teeth and only a few studies have been done on dentin of primary teeth. However, some differences exist between the dentin of permanent and primary teeth, reportedly related to the number of dentinal tubules as well as to the degree of mineralization and inorganic component [1618]. Therefore, the aim of this in vitro study was (1) to qualitatively evaluate the dentin micromorphology of primary teeth after diamond bur and different Er:YAG laser treatments by use of scanning electron microscopy (SEM) and (2) to evaluate the adhesive performance of primary tooth dentin after diamond bur and different Er:
YAG laser treatments by use of the microtensile bond strength ( $\mu$ TBS) method.

\section{Materials and methods}

Qualitative SEM evaluation of dentin micromorphology

Eighteen non-carious, extracted or exfoliated second human primary molars without restorations (gathered at the Department of Preventive, Restorative and Pediatric Dentistry, University of Bern with consent of patient and parent) were selected. The molars were cleaned under tap water, stored in $0.5 \%$ chloramine solution at $4^{\circ} \mathrm{C}$ until use, and embedded in circular molds with self-curing acrylic resin (Paladur, Heraeus Kulzer GmbH, Hanau, Germany). The molars were divided into six groups ( $n=3 /$ group) and treated as described in Table 1. As a clinical reference, molars of group 1a were treated with diamond bur only and molars of group 2a were treated with the Er:YAG laser only. Molars of group $1 b$ and of groups $2 b / c / d$ were previously ground with a grinding machine and silicon carbide (SiC) papers grit \#320 (Struers LaboPol-21/SiC \#320, Struers, Ballerup, Denmark).

Groups $1 \mathrm{a} / \mathrm{b}$ were treated with a cylindrical $40 \mu \mathrm{m}$ grit diamond bur (FG 4305 L, Intensiv, Grancia, Switzerland) in a 1:5 high-speed contra-angle handpiece (GENTLEpower LUX 25 LP, KaVo, Biberach, Germany) with water cooling. The surfaces were diamond bur-treated in three directions at $0^{\circ}, 45^{\circ}$, and $90^{\circ}$.

Groups $2 \mathrm{a} / \mathrm{b} / \mathrm{c} / \mathrm{d}$ were treated with an Er:YAG laser (Er: YAG laser chamber within the handpiece; LiteTouch, Syneron Dental, Yokneam Ilit, Israel) and a laser tip of $14 \mathrm{~mm}$ in length and $1 \mathrm{~mm}$ in diameter. The laser beam was

Table 1 Treatment methods of the different groups

Diamond bur treatment methods

Group 1a (clinical situation):

Group 1b:

ER:YAG laser treatment methods (mean pulse duration: $450 \mu \mathrm{s}$ ) Group 2a (clinical situation, manufacturer's settings):

Group 2b (experimental setting "high"):

Group 2c (manufacturer's setting “finishing”):

Group 2d (experimental setting "low"):
- preparation with a $40 \mu \mathrm{m}$ diamond bur

$(\sim 150 \mathrm{~s})$

- grinding with $\mathrm{SiC}$ grit \#320

- finishing with a $40 \mu \mathrm{m}$ diamond bur

(25-30 s)

- preparation with Er:YAG laser at $200 \mathrm{~mJ} / 25 \mathrm{~Hz}$ (5 W)

- finishing at $100 \mathrm{~mJ} / 35 \mathrm{~Hz}(3.5 \mathrm{~W})$

(preparation+finishing: $>300 \mathrm{~s}$ )

- grinding with $\mathrm{SiC}$ grit \#320

- Er:YAG at $400 \mathrm{~mJ} / 20 \mathrm{~Hz}(8 \mathrm{~W})$

- grinding with $\mathrm{SiC}$ grit \#320

- Er:YAG at $100 \mathrm{~mJ} / 35 \mathrm{~Hz}(3.5 \mathrm{~W})$

(60-90 s)

- grinding with $\mathrm{SiC}$ grit \#320

- Er:YAG at $50 \mathrm{~mJ} / 35 \mathrm{~Hz}(1.75 \mathrm{~W})$

$(100-130 \mathrm{~s})$ 
applied perpendicular to the ground dentin surface at a focal distance of $2 \mathrm{~mm}$ with water cooling. The ground surfaces were irradiated in three directions at $0^{\circ}, 45^{\circ}$, and $90^{\circ}$. The molars of all six groups were treated by the same operator. The range of time needed for surface treatment per molar is listed in Table 1 for all six groups.

After surface treatment, the molars were dehydrated in ethanol solutions of ascending concentrations (40\%, 60\%, $80 \%, 2 \times 100 \%$ ) for $24 \mathrm{~h}$ each and stored in a desiccator until subsequent sputtering: The molars were mounted on aluminum stubs and gold/palladium sputter-coated (100 s, $50 \mathrm{~mA}$ ) using a sputtering device (Balzers SCD 050, Balzers, Liechtenstein). SEM was performed with a Stereoscan S360 scanning electron microscope at $20 \mathrm{kV}$ (Cambridge Instruments, Cambridge, UK). Digital SEM micrographs of $100 \times$ and $4000 \times$ magnification were made of every surface (Digital Image Processing System, Version 2.3.1.0, point electronic $\mathrm{GmbH}$, Halle, Germany).

\section{Microtensile bond strength ( $\mu \mathrm{TBS})$ measurements}

A final amount of 64 non-carious, extracted or exfoliated second human primary molars without restorations (gathered at the Department of Preventive, Restorative and Pediatric Dentistry, University of Bern with consent of patient and parent) were used in this study. The molars were cleaned under tap water and stored in $0.5 \%$ chloramine solution at $4^{\circ} \mathrm{C}$ until use.

For visualization of the dental pulp/residual coronal dentin during further processing, the pulp chamber was retrogradely opened and filled with a colored light-curing compomer restorative material (Twinky Star "pink", VOCO, Cuxhaven, Germany; Lot Nr: 1011453). The molars were then embedded in circular molds with selfcuring acrylic resin (Paladur, Heraeus Kulzer $\mathrm{GmbH}$ ) and ground with a grinding machine and $\mathrm{SiC}$ papers grit \#320 (Struers LaboPol-21/SiC \#320, Struers) until the entire surface was in coronal dentin. Dentin surfaces were checked for absence of residual enamel. Molars exhibiting compomer material through coronal dentin were discarded. The molars were then treated with the diamond bur or the Er:YAG laser as listed in Table 1 for group $1 \mathrm{~b}$ and groups $2 \mathrm{~b} / \mathrm{c} / \mathrm{d}$ ( $n=16 /$ treatment method). The molars of all six groups were treated by the same operator. The range of time needed for surface treatment per molar is listed in Table 1.

Subsequently, the self-etch adhesive Clearfil SE (Kuraray, Okayama, Japan; Primer Lot Nr: 00965AA, Bond Lot $\mathrm{Nr}$ : 01387AA) was applied according to the manufacturer's instructions. After adhesive treatment, the molars were built up in two layers of $2 \mathrm{~mm}$ each with the resin composite Clearfil Majesty Esthetic (Kuraray; shade A4, Lot Nr: 00004GA). Each layer of resin composite was light-cured for $20 \mathrm{~s}$ and all light-curing steps were performed with a LED light-curing unit (Bluephase Polywave, Ivoclar Vivadent AG, Schaan, Liechtenstein) in the "High"-power mode. Light power density was verified to be at least $1,200 \mathrm{~mW} / \mathrm{cm}^{2}$ at the beginning and end of each day of sample preparation.

The primary molars with the resin composite build-up were then stored for $36 \mathrm{~h}$ in $100 \%$ humidity at $37^{\circ} \mathrm{C}$.

After storage, the molars were sectioned with an electronically programmable diamond saw under water cooling (Struers Accutom-5 with Struers Diamond CutOff Wheel 330CA, Struers) perpendicular to the adhesive interface in both $\mathrm{x}$ and $\mathrm{y}$ directions to obtain nine sticks of the centric dentin surface part. In order to monitor the size and to calculate the bonding surface (BSU $\left.\left(\mathrm{mm}^{2}\right)\right)$ of each stick, length and width of the sticks were measured with a digital caliper (Mitutoyo IP 65, Kawasaki, Japan; mean length (standard deviation): 1.05 (0.03) mm, mean width (standard deviation): 1.05 (0.04) mm). The sticks were then fixed by their ends to notched Ciucchi's jigs mounted in a universal testing machine (Syndicad TC-550, Syndicad Dental Research, Munich, Germany) with Heliobond (Ivoclar Vivadent AG). The sticks were stressed in tension at a crosshead speed of $1.0 \mathrm{~mm} / \mathrm{min}$ and the maximum force $\left(\mathrm{F}_{\max }(\mathrm{N})\right)$ was recorded. The $\mu \mathrm{TBS}$ values $(\mathrm{MPa})$ were calculated according to the formula $\mu \mathrm{TBS}=\mathrm{F}_{\max } / \mathrm{BSU}$.

Additionally, the failure mode of each stick was stereomicroscopically determined at $45 \times$ magnification (Leica ZOOM 2000, Leica, Buffalo, NY, USA) and classified into one of the five following categories: (1) adhesive failure between adhesive system and dentin, (2) adhesive failure between adhesive system and resin composite, (3) mixed adhesive failure (failure modes 1 and 2), (4) cohesive failure in dentin, and (5) cohesive failure in resin composite.

Four sticks per tooth were measured and stereomicroscopically analyzed. In the rare cases of pretesting failure (nine pretesting failures/256 final sticks), one of the remaining five sticks of the same tooth was used as a replacement.

\section{Statistical analysis of $\mu$ TBS values}

Out of the four $\mu$ TBS values obtained per primary molar, a mean $\mu$ TBS value was calculated. Therefore, $16 \mu$ TBS values per treatment method were used for statistical analysis. The treatment methods were compared with a Kruskal-Wallis test. The main statistical analysis was performed with $\mathrm{R}$ version 2.9.1 (The R Foundation for Statistical Computing, Vienna, Austria; www.r-project.org).

The $\mu$ TBS data of preliminary tests had been statistically analyzed with NCSS/PASS 2005 (NCSS, Kaysville, UT, 
USA) for sample size determination after the level of significance had been set at $\alpha=0.05$.

\section{Results}

Qualitative SEM evaluation of dentin micromorphology

Qualitative SEM evaluation revealed the same dentin micromorphology for all three specimens in each of the six groups. Representative micrographs of the qualitative SEM evaluation are shown in Fig. 1.
When observed at $100 \times$ magnification, the dentin surfaces of groups $1 \mathrm{a}$ and $1 \mathrm{~b}$ showed a relatively smooth surface with intersecting undulations parallel to the three instrumentation directions. At $4000 \times$ magnification, both surfaces were covered with a uniform smear layer and no dentinal tubules were visible (Figs. 1a/b, small pictures).

Previous grinding with $\mathrm{SiC}$ paper did not affect the micromorphological appearance of surfaces treated with the 40- $\mu \mathrm{m}$ diamond bur (group 1b compared to group 1a).

Laser treatment resulted in substantially different surface micromorphology compared to diamond bur treatment. When observed at $100 \times$ magnification, Er:YAG laser-
Fig. 1 Scanning electron micrographs for qualitative evaluation of dentin micromorphology

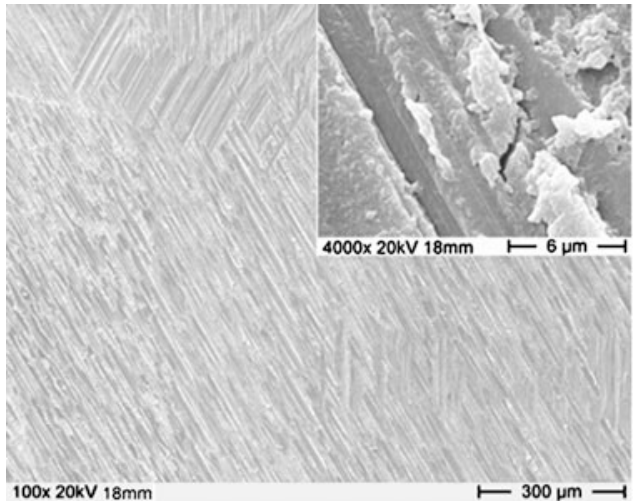

a) Group 1a ( $40 \mu \mathrm{m}$ grit diamond bur)

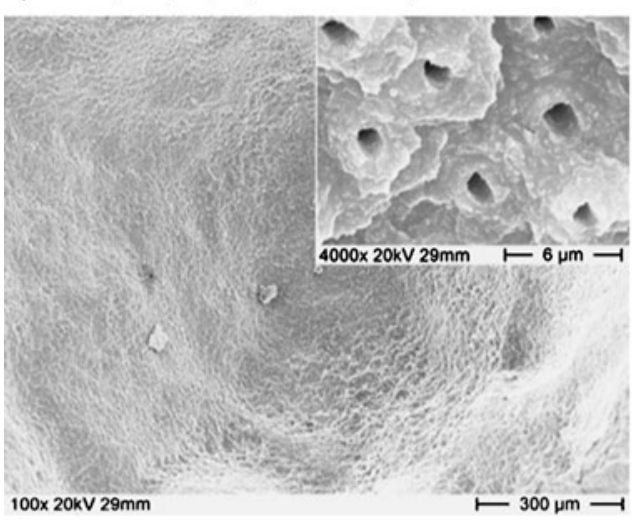

c) Group $2 \mathrm{a}(\mathrm{Er}: Y A G 200 \mathrm{~mJ} / 25 \mathrm{~Hz}+100 \mathrm{~mJ} / 35 \mathrm{~Hz}$ )

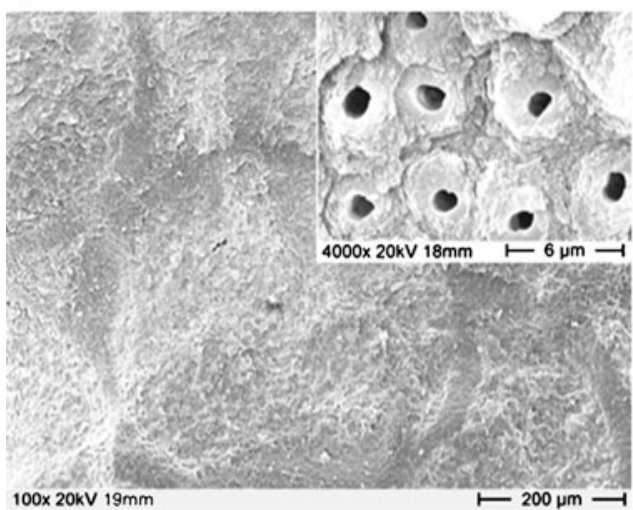

e) Group 2c (ground flat + Er:YAG at $100 \mathrm{~mJ} / 35 \mathrm{~Hz}$ )

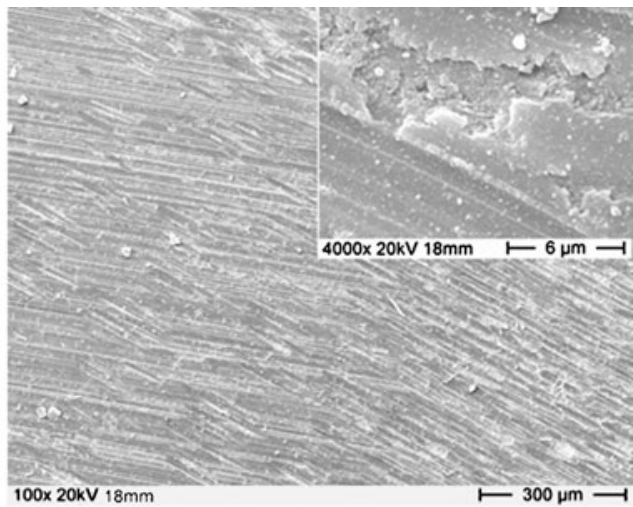

b) Group $1 \mathrm{~b}$ (ground flat $+40 \mu \mathrm{m}$ grit diamond bur)

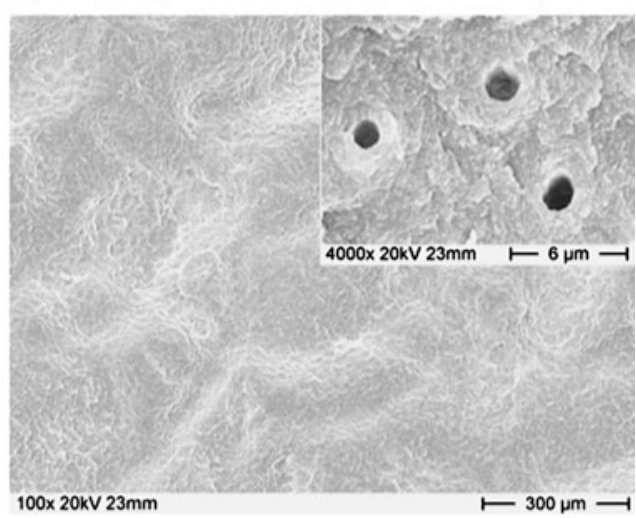

d) Group $2 b$ (ground flat + Er:YAG at $400 \mathrm{~mJ} / 20 \mathrm{~Hz}$ )

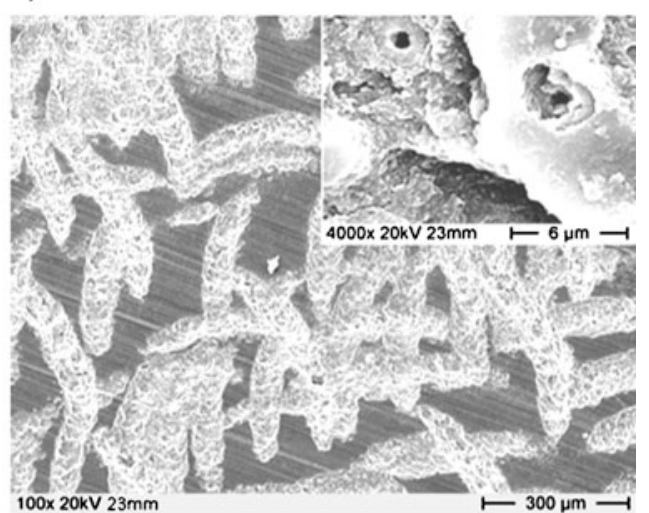

f) Group $2 d$ (ground flat + Er:YAG at $50 \mathrm{~mJ} / 35 \mathrm{~Hz}$ ) 
treated surfaces showed a multiple overlapping circular pattern in groups $2 b$ and $2 c$. However, in group $2 d$, the laser beam had insufficiently irradiated the area, so that the underlying SiC-ground surface was still partly visible (Fig. 1f).

Previous grinding with $\mathrm{SiC}$ paper did not affect the micromorphology after laser irradiation in groups $2 \mathrm{~b}$ and $2 \mathrm{c}$ and thus, the irradiated surface resulted in a micromorphology very similar to the one obtained after the clinical situation with only Er:YAG laser preparation (group 2a). At 4000× magnification, all Er:YAG lasertreated surfaces (groups $2 \mathrm{a} / \mathrm{b} / \mathrm{c} / \mathrm{d}$ ) had a similarly distinctive, irregular, and scaly appearance exhibiting open tubules and absence of smear layer (Figs. 1c-f, small pictures). Intertubular dentin was selectively more ablated than peritubular dentin. However, the micromorphology varied occasionally according to orientation of the dentin tubules. There was no evidence of thermal damages such as cracking or carbonization.

Microtensile bond strength ( $\mu \mathrm{TBS}$ ) measurements

The $\mu$ TBS values of the four groups are shown in Table 2 (median, lower/1st and upper/3rd quartile, and minima/ maxima; mean value and standard deviation). The KruskalWallis test showed no significant differences between the treatment methods $(p=0.394)$.

Table 2 Microtensile bond strength values of the different groups $(n=$ 16/group)

\begin{tabular}{ll}
\hline $\begin{array}{l}\text { Group } \\
\text { (Treatment method) }\end{array}$ & $\begin{array}{l}\text { (lq) median (uq) } \\
\text { (min-max) } \\
\text { Mean value (SD) }\end{array}$ \\
\hline $\begin{array}{l}\text { Group } 1 \mathrm{~b} \\
\text { (grinding }+40 \mu \mathrm{m} \text { grit diamond bur) }\end{array}$ & $\begin{array}{l}(20.6) 23.8(30.0) \\
(14.2-39.4)\end{array}$ \\
Group 2b & $24.8(6.6)$ \\
(grinding+Er:YAG at $400 \mathrm{~mJ} / 20 \mathrm{~Hz})$ & $(23.2) 25.6(29.6)$ \\
& $(20.2-34.0)$ \\
Group 2c & $26.1(4.3)$ \\
(grinding+Er:YAG at $100 \mathrm{~mJ} / 35 \mathrm{~Hz})$ & $(15.3) 21.4(28.6)$ \\
& $(9.6-37.1)$ \\
Group 2d & $22.2(8.6)$ \\
(grinding+Er:YAG at $50 \mathrm{~mJ} / 35 \mathrm{~Hz}$ ) & $(20.2) 23.7(27.8)$ \\
& $(12.4-36.1)$
\end{tabular}

lq=lower/1st quartile; uq=upper/3rd quartile; $\min =\operatorname{minimum;~} \max =$ maximum; $\mathrm{SD}=$ standard deviation
The distribution of failure modes of the four groups is shown in Table 3. Whereas the diamond bur-treated group $1 \mathrm{~b}$ presented a majority of adhesive failures between adhesive system and dentin, the predominant failure mode of the Er:YAG laser-treated groups $2 \mathrm{~b} / \mathrm{c} / \mathrm{d}$ was adhesive failure between adhesive system and resin composite. Similar or equal amounts of mixed adhesive failure or cohesive failure in dentin were observed in all groups except for group $2 \mathrm{~d}$, which presented a higher number of mixed adhesive failures and no case of cohesive failure in dentin.

\section{Discussion}

The micromorphologies of dentin of primary teeth treated with diamond bur or Er:YAG laser were similar to the corresponding ones reported for dentin of permanent teeth, with a uniform smear layer and no visible dentinal tubules for the diamond bur-treated groups and an absence of smear layer and open tubules for the Er:YAG laser-treated groups $[7,8,12,19]$. For all four Er:YAG groups (groups $2 \mathrm{a} / \mathrm{b} / \mathrm{c} /$ d), clinically no evidence of thermal damage such as carbonization was visible on the dentin surfaces, which was confirmed by the SEM micrographs. However, possible pulpal thermal changes may have occurred, especially for the experimental setting "high".

For preparation of $\mu$ TBS-samples, a standardized flat surface was needed. Thus, abrasive papers were used to achieve flat surfaces before diamond bur or Er:YAG laser treatment. A possible influence of previous $\mathrm{SiC}$ grinding on the dentin micromorphology was examined by inclusion of groups 1a and 2a, which served as controls with no $\mathrm{SiC}$ grinding. In general, previous grinding had no influence on the dentin micromorphology. However, in group 2d, the SEM evaluation showed that the low laser energy setting $(50 \mathrm{~mJ} / 35 \mathrm{~Hz}(1.75 \mathrm{~W})$; experimental setting "low") was insufficient for broad ablation and for erasure of all traces of the grinding procedure: Although clinically all dentin surfaces of group $2 \mathrm{~d}$ had the same chalky appearance as the dentin surfaces of the three other Er:YAG groups (groups $2 \mathrm{a} / \mathrm{b} / \mathrm{c}$ ), the SEM micrographs of group $2 \mathrm{~d}$ showed $\mathrm{SiC}$ paper ground dentin surfaces to be clearly visible between traces of the laser irradiation (Fig. 1f). Due to the difficulty in clinically controlling for sufficient ablation, the adhesive performance of group $2 \mathrm{~d}$ was likely to depend on both the $\mathrm{SiC}$ paper and the Er:YAG laser micromorphologies. On dentin of permanent teeth, other studies which used $\mathrm{SiC}$ papers to produce a uniform smear layer and standardized surfaces reported equal or significantly higher bond strength values than those obtained on Er:YAG lasertreated dentin [20-22]. However in the present study, this micromorphology with partly non-ablated areas did not 
Table 3 Failure mode analysis

\begin{tabular}{|c|c|c|c|c|}
\hline Treatment method & $\begin{array}{l}\text { Group } 1 \mathrm{~b} \\
64 \text { sticks } \\
\text { (4 per molar; } \\
n=16 \text { molars) }\end{array}$ & $\begin{array}{l}\text { Group } 2 b \\
64 \text { sticks } \\
\text { (4 per molar; } \\
n=16 \text { molars) }\end{array}$ & $\begin{array}{l}\text { Group 2c } \\
64 \text { sticks } \\
\text { (4 per molar; } \\
n=16 \text { molars) }\end{array}$ & $\begin{array}{l}\text { Group } 2 \mathrm{~d} \\
64 \text { sticks } \\
\text { ( } 4 \text { per molar; } \\
n=16 \text { molars) }\end{array}$ \\
\hline \multicolumn{5}{|l|}{ Failure mode } \\
\hline $\begin{array}{l}\text { Adhesive between adhesive } \\
\text { system and dentin }\end{array}$ & $54 \%$ & $23 \%$ & $22 \%$ & $9 \%$ \\
\hline $\begin{array}{l}\text { Adhesive between adhesive } \\
\text { system and composite }\end{array}$ & $16 \%$ & $53 \%$ & $54 \%$ & $53 \%$ \\
\hline Mixed adhesive failure & $28 \%$ & $22 \%$ & $22 \%$ & $38 \%$ \\
\hline Cohesive in Dentin & $2 \%$ & $2 \%$ & $2 \%$ & $0 \%$ \\
\hline Cohesive in Composite & $0 \%$ & $0 \%$ & $0 \%$ & $0 \%$ \\
\hline
\end{tabular}

enhance the $\mu \mathrm{TBS}$ : No statistically significant differences among the four treatment methods were found and group $2 \mathrm{~d}$ did not reach higher $\mu$ TBS values than the other laser groups. It may be that the three laser energy settings of groups $2 \mathrm{~b} / \mathrm{c} / \mathrm{d}$ did not lead to different $\mu$ TBS values, but they did vary in the speed of ablation. Generally, Er:YAG laser treatment was more time-consuming than diamond bur treatment. Among the groups with different laser energy settings, there was a faster ablation with higher laser energy settings. Correlations between Er:YAG laser energy settings, ablation time, and pulpal thermal changes during laser preparation of primary teeth should be investigated in further studies.

Information about bond strength on Er:YAG laser-treated dentin of primary teeth is sparse. On dentin of permanent teeth, however, there are several studies that confirm the findings of this study and in which bond strength values did not differ significantly among the treatment methods. In a study of Ramos and coworkers, equal tensile bond strength values of Clearfil $\mathrm{SE}$ were reached on $\mathrm{SiC}$ paper-ground dentin and on dentin irradiated with two laser settings [22]. Gurgan and coworkers showed no significant differences in bond strength of a two-step, self-etch adhesive system when used on diamond bur-treated or on Er:YAG lasertreated dentin [23]. Carrieri and coworkers reported no significant differences in tensile bond strength on dentin treated with three different laser settings [13]. However, the dentin had been etched and a resin cement, and not a resin composite, was used. The studies available with bond strength measurements on Er:YAG laser-treated dentin of primary teeth reported shear bond strength values from 10.4 to $12.3 \mathrm{MPa}$ and from 5.1 to $9.7 \mathrm{MPa}$, depending on the adhesive system and the method used [24, 25]. In literature, shear bond strength values on dentin of permanent teeth vary widely from 4.0 to $41.9 \mathrm{MPa}[11,15,20,23,26]$ and can therefore hardly be compared to those obtained on dentin of primary teeth. Also, studies investigating the tensile or microtensile bond strength between Clearfil SE and dentin of permanent teeth treated with Er:YAG laser have shown a wide range of values from $12.7 \mathrm{MPa}$ to 40.9 $\mathrm{MPa}[7,12,22,27,28]$.

In the present study, there was a difference between the diamond bur and the Er:YAG laser groups in their distribution of failure modes. The diamond bur group $1 \mathrm{~b}$ presented adhesive failure between adhesive system and dentin in $54 \%$ of the samples and adhesive failure between adhesive system and resin composite in $16 \%$. The three Er: YAG laser groups presented the opposite distribution with adhesive failure between adhesive system and dentin in 9$23 \%$ of the samples and adhesive failure between adhesive system and resin composite in 53-54\%. As previously shown, the self-etch adhesive Clearfil SE interacts superficially with bur-treated dentin, forming a relatively thin hybrid layer and preserving the smear layer in the tubules $[29,30]$. The fact that there were fewer adhesive failures between adhesive system and dentin in the Er:YAG laser groups compared to the diamond bur group may be due to increased chemical bonding and micromechanical interlocking to a dentin surface exhibiting no smear layer and open tubules, making the interface between adhesive system and resin composite the weakest link.

The failure mode pattern suggests that Clearfil SE has an acceptable bonding potential to Er:YAG laser-treated dentin of primary molars. This could be in accordance with the findings comparing Clearfil SE to other adhesive systems on dentin of permanent teeth: Clearfil SE reached equal tensile bond strength values to an etch-and-rinse adhesive system [22], and in a second study, Clearfil SE reached higher shear bond strength values than two other self-etch adhesive systems [15]. Both studies were conducted on Er: YAG laser-treated dentin of permanent teeth. Future studies should compare different adhesive systems on laser-treated dentin of primary molars.

In conclusion, the $\mu$ TBS values of the present study did not differ significantly between the treatment methods, including different laser energy settings. Thus, 
dentin of primary molars treated with Er:YAG laser provided bond strengths to resin composite similar to those provided with diamond bur-treated dentin. Nevertheless, it is of importance to further investigate combinations of laser-treated primary teeth and different adhesive systems to establish the Er:YAG laser application also in pediatric dentistry.

Acknowledgments The authors would like to thank Kuraray Europe, Germany and VOCO, Germany, for providing the materials needed. Furthermore, we thank S. Hayoz and Prof. Dr. J. Hüsler, Institute of Mathematical Statistics and Actuarial Science, University of Bern for statistical advice.

Conflicts of interest The authors declare no conflicts of interest, real or perceived, financial or nonfinancial.

\section{References}

1. Keller U, Hibst R (1997) Effects of Er:YAG laser in caries treatment: a clinical pilot study. Lasers Surg Med 20(1):32-38

2. Trajtenberg CP, Pereira PN, Powers JM (2004) Resin bond strength and micromorphology of human teeth prepared with an erbium:YAG laser. Am J Dent 17(5):331-336

3. Amaral FL, Colucci V, de Souza-Gabriel AE, Chinelatti MA, Palma-Dibb RG, Corona SA (2008) Adhesion to Er:YAG laserprepared dentin after long-term water storage and thermocycling. Oper Dent 33(1):51-58

4. Keller U, Hibst R, Geurtsen W, Schilke R, Heidemann D, Klaiber B, Raab WH (1998) Erbium:YAG laser application in caries therapy. Evaluation of patient perception and acceptance. J Dent 26(8):649-656

5. Armengol V, Jean A, Rohanizadeh R, Hamel H (1999) Scanning electron microscopic analysis of diseased and healthy dental hard tissues after Er:YAG laser irradiation: in vitro study. J Endod 25 (8):543-546

6. Freitas PM, Navarro RS, Barros JA, de Paula EC (2007) The use of Er:YAG laser for cavity preparation: an SEM evaluation. Microsc Res Tech 70(9):803-808

7. Cardoso MV, Coutinho E, Ermis RB, Poitevin A, Van Landuyt K, De Munck J, Carvalho RC, Van Meerbeek B (2008) Influence of dentin cavity surface finishing on micro-tensile bond strength of adhesives. Dent Mater 24(4):492-501

8. Cardoso MV, Coutinho E, Ermis RB, Poitevin A, Van Landuyt K, De Munck J, Carvalho RC, Lambrechts P, Van Meerbeek B (2008) Influence of Er,Cr:YSGG laser treatment on the microtensile bond strength of adhesives to dentin. J Adhes Dent 10 (1):25-33

9. Curti M, Rocca JP, Bertrand MF, Nammour S (2004) Morphostructural aspects of Er:YAG-prepared class V cavities. J Clin Laser Med Surg 22(2):119-123

10. Bader C, Krejci I (2006) Indications and limitations of Er:YAG laser applications in dentistry. Am J Dent 19(3):178-186

11. Bahrami B, Askari N, Tielemans M, Heysselaer D, Lamard L, Peremans A, Nyssen-Behets C, Nammour S (2010) Effect of low fluency dentin conditioning on tensile bond strength of composite bonded to Er:YAG laser-prepared dentin: a preliminary study. Lasers Med Sci [Epub ahead of print]

12. Manhães L, Oliveira DC, Marques MM, Matos AB (2005) Influence of Er:YAG laser surface treatment and primer application methods on microtensile bond strength self-etching systems. Photomed Laser Surg 23(3):304-312
13. Carrieri TC, de Freitas PM, Navarro RS, Eduardo Cde P, Mori M (2007) Adhesion of composite luting cement to Er:YAG-lasertreated dentin. Lasers Med Sci 22(3):165-170

14. Amaral FL, Colucci V, Souza-Gabriel AE, Chinelatti MA, PalmaDibb RG, Corona SA (2010) Bond durability in erbium:yttriumaluminum-garnet laser-irradiated enamel. Lasers Med Sci 25 (2):155-163

15. Brulat N, Rocca JP, Leforestier E, Fiorucci G, Nammour S, Bertrand MF (2009) Shear bond strength of self-etching adhesive systems to Er:YAG-laser-prepared dentin. Lasers Med Sci 24 (1):53-57

16. Sumikawa DA, Marshall GW, Gee L, Marshall SJ (1999) Microstructure of primary tooth dentin. Pediatr Dent 21(7):439444

17. Schilke R, Lisson JA, Bauss O, Geurtsen W (2000) Comparison of the number and diameter of dentinal tubules in human and bovine dentine by scanning electron microscopic investigation. Arch Oral Biol 45(5):355-361

18. Kornblit R, Bossù M, Mari D, Rocca JP, Polimeni A (2009) Enamel and dentine of deciduous teeth Er:YAG laser prepared. A SEM study. Eur J Paediatr Dent 10(2):75-82

19. Tachibana A, Marques MM, Soler JM, Matos AB (2008) Erbium, chromium:yttrium scandium gallium garnet laser for caries removal: influence on bonding of a self-etching adhesive system. Lasers Med Sci 23(4):435-441

20. de Carvalho RC, de Freitas PM, Otsuki M, de Eduardo CP, Tagami J (2008) Micro-shear bond strength of Er:YAG-lasertreated dentin. Lasers Med Sci 23(2):117-124

21. Ferreira LS, Apel C, Francci C, Simoes A, Eduardo CP, Gutknecht N (2010) Influence of etching time on bond strength in dentin irradiated with erbium lasers. Lasers Med Sci 25(6):849-854

22. Ramos AC, Esteves-Oliveira M, Arana-Chavez VE, de Paula EC (2010) Adhesives bonded to erbium:yttrium-aluminum-garnet laser-irradiated dentin: transmission electron microscopy, scanning electron microscopy and tensile bond strength analyses. Lasers Med Sci 25(2):181-189

23. Gurgan S, Kiremitci A, Cakir FY, Yazici E, Gorucu J, Gutknecht N (2009) Shear bond strength of composite bonded to erbium: yttrium-aluminum-garnet laser-prepared dentin. Lasers Med Sci 24(1):117-122

24. Monghini EM, Wanderley RL, Pécora JD, Palma Dibb RG, Corona SA, Borsatto MC (2004) Bond strength to dentin of primary teeth irradiated with varying Er:YAG laser energies and SEM examination of the surface morphology. Lasers Surg Med 34 (3):254-259

25. Scatena C, Torres CP, Gomes-Silva JM, Contente MM, Pécora JD, Palma-Dibb RG, Borsatto MC (2010) Shear strength of the bond to primary dentin: influence of Er:YAG laser irradiation distance. Lasers Med Sci [Epub ahead of print]

26. Ceballo L, Toledano M, Osorio R, Tay FR, Marshall GW (2002) Bonding to Er-YAG-laser-treated dentin. J Dent Res 81(2):119-122

27. Van Meerbeek B, De Munck J, Mattar D, Van Landuyt K, Lambrechts P (2003) Microtensile bond strengths of an etch\&rinse and self-etch adhesive to enamel and dentin as a function of surface treatment. Oper Dent 28(5):647-660

28. Bakry AS, Nakajima M, Otsuki M, Tagami J (2009) Effect of Er: YAG laser on dentin bonding durability under simulated pulpal pressure. J Adhes Dent 11(5):361-368

29. De Munck J, Vargas M, Iracki J, Van Landuyt K, Poitevin A, Lambrechts P, Van Meerbeek B (2005) One-day bonding effectiveness of new self-etch adhesives to bur-cut enamel and dentin. Oper Dent 30(1):39-49

30. Van Meerbeek B, De Munck J, Yoshida Y, Inoue S, Vargas M, Vijay P, Van Landuyt K, Lambrechts P, Vanherle G (2003) Buonocore memorial lecture. Adhesion to enamel and dentin: current status and future challenges. Oper Dent 28(3):215-235 